\title{
Spectroscopic Evidence for Unusual Microviscosity in Imidazolium Ionic Liquid and Tetraethylene Glycol Dimethyl Ether Cosolvent Mixtures
}

\author{
Boxuan Li, Yingying Wang, Xuefei Wang, Silvije Vdovic, Qianjin Guo,* and Andong Xia* \\ The State Key Laboratory of Molecular Reaction Dynamics, Institute of Chemistry, Chinese Academy of Sciences, Beijing 100190, \\ P. R. China \\ Beijing National Laboratory for Molecular Sciences (BNLMS), Institute of Chemistry, Chinese Academy of Sciences, Beijing 100190, \\ P. R. China
}

ABSTRACT: The rotational dynamics of coumarin 153 (C153) in imidazolium-based ionic liquid 1-butyl-3-methylimidazolium hexafluorophosphate $\left([\mathrm{bmim}]\left[\mathrm{PF}_{6}\right]\right)$ and tetraethylene glycol dimethyl ether (TEGDME) mixtures across all mole fractions have been investigated to determine the local viscosity of the microenvironment surrounding the probe molecules. The excimer-to-monomer fluorescence emission intensity ratio $\left(I_{\mathrm{E}} / I_{\mathrm{M}}\right)$ of a well-known microviscosity probe, 1,3-bis(1-pyrenyl)propane (BPP), is also employed to study

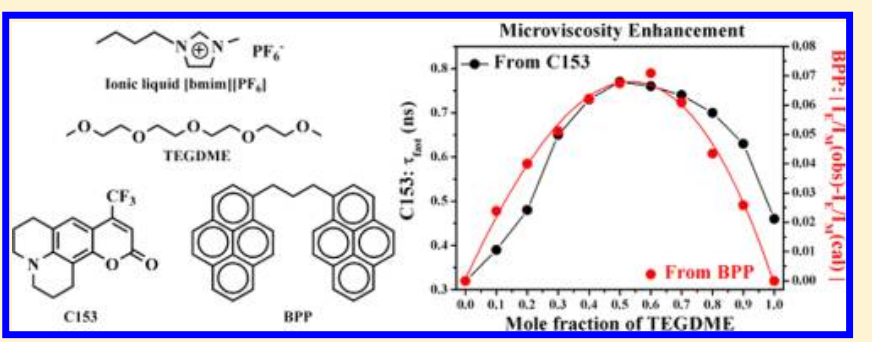
the microviscosity of the mixtures as a complementary measurement. The rotational dynamics of $\mathrm{C} 153$ show that there are incompact and compact domains within the heterogeneous structural $[\mathrm{bmim}]\left[\mathrm{PF}_{6}\right]$, resulting in fast and slow components of $\mathrm{C} 153$ rotational dynamics. The microviscosity in different structural domains of $[\mathrm{bmim}]\left[\mathrm{PF}_{6}\right]$ before and after adding cosolvent TEGDME with different mole fractions is further investigated by studying the fluorescence anisotropy decay of probe molecules. The obtained average rotation time constants show that the microviscosity of $[\mathrm{bmim}]\left[\mathrm{PF}_{6}\right]$ is enhanced after mixing with a certain amount of TEGDME, although the bulk viscosity of TEGDME itself is much lower than that of the ionic liquid. This unusual behavior of microviscosity enhancement is further proven by the steady state fluorescence measurement with the microviscosity probe of BPP. The microviscosity enhancement is reasonably demonstrated by the fast time constant of C153 rotational dynamics and the departure between the experimentally observed and calculated ratio of $I_{\mathrm{E}} / I_{\mathrm{M}}$ of BPP, which shows that this effect is most pronounced at intermediate mole fractions of the $[\mathrm{bmim}]\left[\mathrm{PF}_{6}\right]$ and TEGDME mixtures. The strengthening effects caused by the molecular interactions between TEGDME and structural heterogeneous ionic liquid $[\mathrm{bmim}]\left[\mathrm{PF}_{6}\right]$ are proposed to interpret the unusual microviscosity behaviors.

\section{INTRODUCTION}

Room temperature ionic liquids (RTILs), with several special properties such as negligible vapor pressure, high thermal and chemical stability, and broad electrochemical window, have received a great deal of attention, which emerged as potential environmentally benign solvents for a large number of reactions, catalysis, separation, and electrochemical studies. ${ }^{1-5}$ Especially, consisting of organic cation and organic/inorganic anion, RTILs are usually able to dissolve various organic and inorganic compounds, which makes them more environmental friendly solvents with respect to the conventional volatile organic compounds. ${ }^{6-10}$ Moreover, RTILs can be designed for many specific properties by choosing proper cationic and anionic components or mixing them with other solvent media, which makes them even more attractive. Therefore, a deep insight into the solvent property of RTILs, especially the microenvironmental property, is a key factor to design the new RTILs and extend their applications.

The UV-visible absorption, fluorescence spectroscopic, time-resolved fluorescence spectroscopic, as well as many other spectroscopic studies have been carried out to investigate the physicochemical properties of RTILs by several groups such as the Samanta group, ${ }^{11-15}$ Maroncelli group, ${ }^{16-20}$ Sarkar group, ${ }^{21-23}$ Quitevis group, ${ }^{24-28}$ Bhattacharyya group, ${ }^{29-33}$ and so on. ${ }^{34-36}$ These studies revealed that the nature of RTILs is more complicated than conventional solvents due to the presence of structural heterogeneity of the microenvironment in RTILs, which affects the solvation and rotational dynamics and other processes of the solute in RTILs. ${ }^{16,29,33}$ Furthermore, molecular dynamics (MD) simulation studies have indicated that RTILs based on the 1-alkyl-3-methylimidazolium cation $\left(\left[\mathrm{C}_{n} \mathrm{mim}\right]^{+}\right)$with alkyl chains $\mathrm{C}_{4}$ and longer are spatially heterogeneous, ${ }^{37-41}$ where two types of structural domains with alkyl chains of $\mathrm{C}_{4}$ or longer in the ionic liquid were expected. Nonpolar domains arising from aggregation of the alkyl chains are formed mainly through the weak essentially van der Waals interactions, and polar domains arising from charge ordering of the anions and imidazolium rings of the cations are

Received: May 21, 2012

Revised: September 5, 2012

Published: October 18, 2012 
formed through the strong electrostatic interactions. The nonpolar and polar domains are interconnected and permeated into a nanostructurally organized network. Our previous study also suggested that, in some imidazolium-based ionic liquids with short alkyl chains less than $\mathrm{C}_{4}$, a hydrogen bond probably resulted in their structural heterogeneity related to an ordered microscopic network, instead of random intermolecular interaction. ${ }^{42}$ Many specific features, such as the significant difference between the bulk viscosity and microviscosity, have been observed due to this heterogeneous nature in RTILs. ${ }^{43}$

Recently, a growing number of studies focused on the investigation of the physicochemical properties of the mixtures of RTILs and conventional solvents because the fine-turning solvent property after adding conventional solvents may broaden the scope of the applications of the RTILs. ${ }^{44-57}$ Many studies on the effects of water, alcohols, and other polar or nonpolar organics in RTILs were carried out. It is found that the addition of a cosolvent into RTILs results in a series of significant changes to physicochemical properties of RTILs such as the viscosity, ${ }^{44-46}$ polarity, ${ }^{47-49}$ and solvation and rotational dynamics. ${ }^{50-54}$ For example, the presence of hydrogen-bonding interaction between RTILs and cosolvent molecules could reduce the electrostatic attraction between cations and anions in ionic liquids, and in turn decrease the overall cohesive energy, resulting in a decrease in viscosity. ${ }^{52-54}$ In addition, a microviscosity enhancement was recently observed in the mixture of imidazolium-based ionic liquid 1butyl-3-methylimidazolium hexafluorophosphate ([bmim]$\left[\mathrm{PF}_{6}\right]$ ) and poly(ethylene glycol) (PEG) in comparison to the individual solvent. ${ }^{55}$ The formation of a hydrogen-bonded network by $[\mathrm{bmim}]\left[\mathrm{PF}_{6}\right]$ with PEG had been considered to be the main reason for the observed microviscosity enhancement. ${ }^{55-57}$

Anyway, most of these previous studies mainly paid attention to microviscosity changes of cosolvents which mainly affect the polar domains of ionic liquid through the hydrogen-bonding effect involved in cations and/or anions of ionic liquid and cosolvent mixtures. To fully understand the microviscosity in a hybrid system including an ionic liquid with different structural domains such as $[\mathrm{bmim}]\left[\mathrm{PF}_{6}\right]$, it is better to choose a cosolvent, which can influence polar and nonpolar domains of the ionic liquid at the same time. Tetraethylene glycol dimethyl ether (TEGDME) can be a more proper candidate as a cosolvent with $[\mathrm{bmim}]\left[\mathrm{PF}_{6}\right]$ to study the interactions and properties of the polar and nonpolar domains in such a hybrid system. It is expected that TEGDME could interact with the imidazolium ring of $[\mathrm{bmim}]\left[\mathrm{PF}_{6}\right]$ cations in polar domains through the hydrogen-bonding effect with the ethers of TEGDME which may act as a hydrogen bond acceptor proved by previous studies, ${ }^{5-57}$ and TEGDME could also affect the nonpolar domains in $[\mathrm{bmim}]\left[\mathrm{PF}_{6}\right]$ composed from the nonpolar butyl side chain of $[\mathrm{bmim}]\left[\mathrm{PF}_{6}\right]$ through van der Waals interactions. Furthermore, unlike water or ethanol, TEGDME and $[\mathrm{bmim}]\left[\mathrm{PF}_{6}\right]$ are completely miscible; therefore, we can obtain the mixtures with any mole fractions of the two neat compositions, which provides a larger range for scrutinizing the molecular interaction. The significance of this study is twofold. First, the microviscosity of polar domians in [bmim $]\left[\mathrm{PF}_{6}\right]$ is expected to decrease because the cosolvent screens the Coulombic interactions between ions of ionic liquid. Second, the TEGDME molecules could possibly increase the microviscosity of nonpolar domains via van der Waals interactions with the alkyl chain of $\left[\mathrm{bmim}^{2}\right]\left[\mathrm{PF}_{6}\right]$. Thus, it is a crucial aspect of investigating the properties of the structural heterogeneous microevironment like microviscosity about RTILs and their mixtures with other cosolvents.

In the present work, we try to reveal the microviscosity in such a hybrid system of $[\mathrm{bmim}]\left[\mathrm{PF}_{6}\right]$ with TEGDME by studying the time-resolved fluorescence spectroscopy of coumarin $153(\mathrm{C} 153)$ and the steady-state fluorescence emission spectra of 1,3-bis(1-pyrenyl)propane (BPP). The structures of $[\mathrm{bmim}]\left[\mathrm{PF}_{6}\right]$, TEGDME, and fluorescent probes used in the present study are shown in Scheme 1. C153 is

Scheme 1. Structure of the $[\mathrm{bmim}]\left[\mathrm{PF}_{6}\right]$, TEGDME, and Probe Molecules C153 and BPP

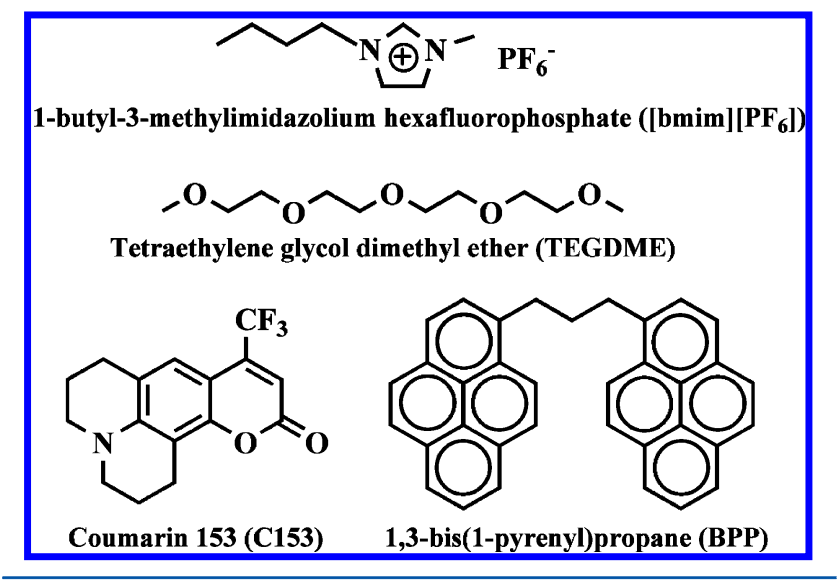

considered to be an ideal probe because the dynamics probed by $\mathrm{C} 153$ have been found to be primarily related to nonspecific solute-solvent interactions in many RTIL systems. ${ }^{17,52,53,58}$ BPP is a particularly sensitive probe of microviscosity especially in the heterogeneous environment such as ionic liquid systems. ${ }^{55-57,59-62}$ As a result, the microviscosity enhancement effects in the $[\mathrm{bmim}]\left[\mathrm{PF}_{6}\right]$ and TEGDME hybrid system were observed by probing the microviscosity through the two complementary experimental methods. Both the methods with excimer-to-monomer fluorescence emission intensity ratio of a well-known microviscosity probe, 1,3-bis(1-pyrenyl)propane (BPP), and the rotational dynamics of $\mathrm{C} 153$ show similar microviscosity enhancement effects which exist in the [bmim]$\left[\mathrm{PF}_{6}\right]$ and TEGDME hybrid system.

\section{MATERIALS AND EXPERIMENTAL METHODS}

2.1. Materials. Ionic liquid $[\mathrm{bmim}]\left[\mathrm{PF}_{6}\right]$ (purity $>99 \%$, water content $<500 \mathrm{ppm}$ ) was purchased from Lanzhou Greenchem ILS, LICP, CAS, China, and stored under a dry nitrogen atmosphere. TEGDME (purity 99\%) was obtained from Adamas. C153 and BPP were from Aldrich and Invitrogen, respectively, and used as received. The concentrations of $\mathrm{C} 153$ and BPP in all samples are about $1.25 \times 10^{-5}$ and $1.0 \times 10^{-6} \mathrm{M}$, respectively.

2.2. Steady-State Spectroscopy. Ultraviolet/visible (UV/ vis) absorption and fluorescence emission spectra were recorded on a spectrophotometer (UV1601, Shimadzu, Japan) and a fluorescence spectrometer (F4500, Hitachi, Japan), respectively. All the measurements were carried out at room temperature.

2.3. Time-Resolved Fluorescence Anisotropy Measurements. The time-resolved fluorescence anisotropy measurements were carried out using a time-correlated singlephoton counting (TCSPC) spectrometer (F900, Edinburgh 
Instrument). The samples were excited at $442 \mathrm{~nm}$ using an 80 ps laser diode (PicoQuant PDL 808). The instrument response function (IRF) of the detection system is 200 ps. The fluorescence anisotropy was measured by using the singlechannel method. An expression for time-resolved anisotropic decay $r(t)$ is given by

$$
r(t)=\frac{I_{\|}(t)-G I_{\perp}(t)}{I_{\|}(t)+2 G I_{\perp}(t)}
$$

where $I_{\|}(t)$ and $I_{\perp}(t)$ are the fluorescence decays polarized parallel and perpendicular to the polarization of the excitation light, respectively, when the excitation polarizer is mounted vertically. The factor $G$ is the ratio of the sensitivity of the detection system for vertically and horizontally polarized light when the excitation polarizer is mounted horizontally. ${ }^{63}$

\section{RESULTS AND DISCUSSION}

3.1. Steady-State Behavior of C153. The absorption and fluorescence spectra of C153 (Scheme 1) in $\left[\mathrm{bmim}^{-}\left[\mathrm{PF}_{6}\right]\right.$ and TEGDME mixtures are shown in Figure 1, and the extracted data are listed in Table 1.

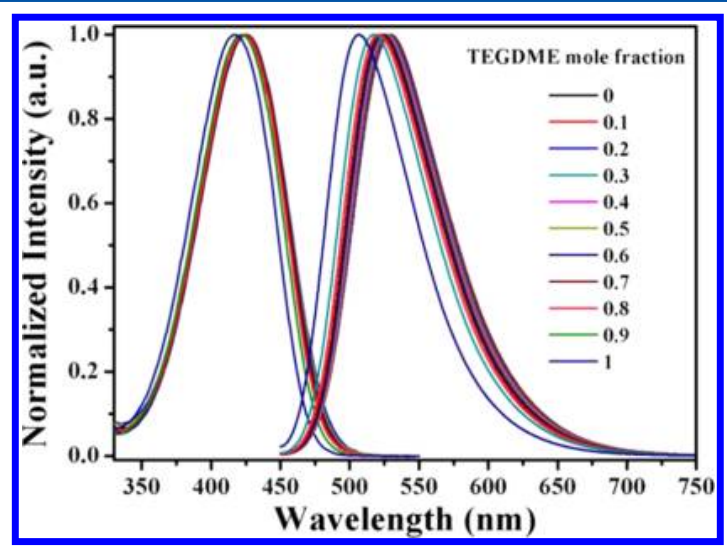

Figure 1. Steady-state absorption (left) and emission (right) spectra of C153 in $[\mathrm{bmim}]\left[\mathrm{PF}_{6}\right]$ and TEGDME mixtures of different compositions. The emission spectra are obtained under the excitation $\left(\lambda_{\text {exc }}\right)$ at $430 \mathrm{~nm}$. All spectra are normalized at the corresponding peak maxima.

Table 1. Steady-State Absorption and Fluorescence Properties of $\mathrm{C} 153$ in $[\mathrm{bmim}]\left[\mathrm{PF}_{6}\right]$ and TEGDME Mixtures

$\begin{array}{ccccc}\chi_{\mathrm{TEGDME}}{ }^{a} & \lambda_{\mathrm{Abs}}{ }^{b}(\mathrm{~nm}) & \lambda_{\mathrm{Em}}{ }^{c}(\mathrm{~nm}) & \Delta \nu^{d}\left(\mathrm{~cm}^{-1}\right) & \lambda_{\mathrm{s}}{ }^{e} \times 10^{7}\left(\mathrm{~cm}^{-1}\right) \\ 0 & 424 & 529 & 4681 & 2.74 \\ 0.1 & 425 & 529 & 4625 & 2.80 \\ 0.2 & 425 & 528 & 4590 & 2.79 \\ 0.3 & 425 & 528 & 4590 & 2.63 \\ 0.4 & 425 & 526 & 4518 & 2.66 \\ 0.5 & 425 & 525 & 4481 & 2.70 \\ 0.6 & 425 & 524 & 4445 & 2.57 \\ 0.7 & 424 & 523 & 4465 & 2.58 \\ 0.8 & 424 & 521 & 4391 & 2.57 \\ 0.9 & 422 & 518 & 4392 & 2.48 \\ 1 & 417 & 507 & 4257 & 2.50\end{array}$

${ }^{a}$ The mole fraction of TEGDME in $[\mathrm{bmim}]\left[\mathrm{PF}_{6}\right]$ and TEGDME mixtures. ${ }^{b}$ The absorption peak wavelength. ${ }^{c}$ The fluorescence emission peak wavelength. ${ }^{d}$ The Stokes shift. ${ }^{e}$ The solvent reorganization energy.
The C153 absorption and fluorescence behaviors in neat $[$ bmim $]\left[\mathrm{PF}_{6}\right]$ agree with previous studies. ${ }^{17,52,58}$ The absorption peak of C153 is almost unaffected (between 424 and 425 $\mathrm{nm}$ ) in the mixtures with the mole fraction of TEGDME from 0 to 0.8 , and blue-shifted to $417 \mathrm{~nm}$ with further addition of TEGDME. The emission maxima of $\mathrm{C} 153$ in $[\mathrm{bmim}]\left[\mathrm{PF}_{6}\right]$ and TEGDME mixtures are gradually blue-shifted from 529 to 507 $\mathrm{nm}$ with the TEGDME mole fraction increased from 0 to 1 . With the gradual addition of TEGDME, the fluorescence Stokes shifts $\left(\Delta \nu=\nu_{\mathrm{Abs}}-\nu_{\mathrm{Em}}\right)$ of $\mathrm{C} 153$ decrease from 4681 to $4257 \mathrm{~cm}^{-1}$.

In solution phase, the solvent reorganization energy $\left(\lambda_{\mathrm{s}}\right)$ is widely used as a measure of the interactions between the chromophore and its surrounding solvent and as a parameter of the polarity of solvent. ${ }^{64}$ The solvent reorganization energy from the steady-state spectra is given as

$$
\lambda_{\mathrm{s}}=\frac{\hbar}{2} \int_{0}^{\infty} \varpi\left[\sigma_{\mathrm{a}}(\varpi)-\sigma_{\mathrm{f}}(\varpi)\right] \mathrm{d} \varpi
$$

where $\sigma_{\mathrm{a}}(\varpi)$ and $\sigma_{\mathrm{f}}(\varpi)$ are the normalized absorption and emission spectra and $\varpi$ is the frequency. The estimated values of $\lambda_{\mathrm{s}}$ of $\mathrm{C} 153$ molecules in $[\mathrm{bmim}]\left[\mathrm{PF}_{6}\right]$ and TEGDME mixtures are also listed in Table 1 . Generally, the $\lambda_{\mathrm{s}}$ values are between the neat $[\mathrm{bmim}]\left[\mathrm{PF}_{6}\right]$ and TEGDME, and gradually decrease with the addition of TEGDME. Therefore, from both the Stokes shifts and the solvent reorganization energy $\left(\lambda_{\mathrm{s}}\right)$ of C153, we conclude that the polarities of these mixtures are between the neat $[\mathrm{bmim}]\left[\mathrm{PF}_{6}\right]$ and TEGDME and do not show any specific behaviors such as "hyperpolarity".

3.2. Rotational Dynamics of $\mathbf{C} 153$. The rotational dynamics of excited probe molecules are very sensitive to the microstructure and the local viscosity of the microenvironment around the probe molecule. ${ }^{65}$ In our previous study, the microviscosity enhancement in neat RTILs induced by a hydrogen-bonding effect was successfully investigated through observing the rotational dynamics of the excited probe. ${ }^{42}$ To determine the effect of the solvent-solvent interactions on the microviscosity in $[\mathrm{bmim}]\left[\mathrm{PF}_{6}\right]$ and TEGDME mixtures, we further perform the time-resolved fluorescence anisotropic measurements of the excited $\mathrm{C} 153$ molecules by using the TCSPC techniques. The anisotropy decay profiles are well fitted with a biexponential function $(x=2)$ when the TEGDME mole fraction is from 0 to 0.8 in the mixtures, and a single exponential function $(x=1)$ with the mole fraction of TEGDME from 0.9 to 1 by eq 3 .

$$
r(t)=\sum_{i=1}^{x} a_{i} \mathrm{e}^{-t / \tau_{i}}
$$

where $a_{i}$ is the amplitude and $\tau_{i}$ is the time constant. The average rotational relaxation time $\left\langle\tau_{\mathrm{r}}\right\rangle$ was calculated using eq 4 . Three typical anisotropy decay profiles are shown in Figure 2, and all the corresponding fitted parameters are listed in Table 2 .

$$
\left\langle\tau_{\mathrm{r}}\right\rangle=\sum_{i=1}^{2} a_{i} \tau_{i} / \sum_{i=1}^{2} a_{i}
$$

As shown in Figure 2 and Table 2, two different time constants are obtained by fitting the decay of the time-resolved anisotropy of $\mathrm{C} 153$ in neat $[\mathrm{bmim}]\left[\mathrm{PF}_{6}\right]$. The fitted values of the fast decay time constant $\left(\tau_{1}\right)$ and the slow decay time constant $\left(\tau_{2}\right)$ in neat ionic liquid are about $0.32(49 \%)$ and 4.90 


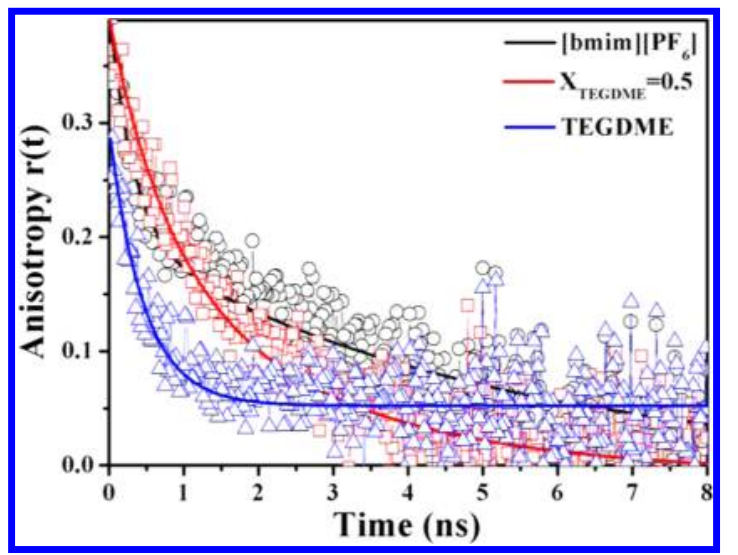

Figure 2. Three typical decays of the time-resolved fluorescence anisotropy, $r(t)$, of $\mathrm{C} 153$ in [bmim] $\left[\mathrm{PF}_{6}\right]$ and TEGDME mixtures with the mole fractions of TEGDME of 0 ([bmim] $\left.\left[\mathrm{PF}_{6}\right]\right), 0.5$, and 1 (TEGDME), respectively. The solid line represents the fitting result.

(51\%) ns, respectively. The observed average rotational relaxation time of $\mathrm{C} 153$ in neat $[\mathrm{bmim}]\left[\mathrm{PF}_{6}\right]$ is $2.66 \mathrm{~ns}$. Since there is not any special frictional coupling between the C153 probe molecules and $[\mathrm{bmim}]\left[\mathrm{PF}_{6}\right],{ }^{17,52,53,58}$ the measured rotational relaxation time is mainly correlated with the local viscosity of the microenvironment around C153. It is expected that there are two types of domains with different microviscosities related to the fast and slow rotational dynamics experienced by $\mathrm{C} 153$ due to the heterogeneous nature of ionic liquid. ${ }^{16,29,33}$ The cation of $[\mathrm{bmim}]\left[\mathrm{PF}_{6}\right]$ is composed of a polar headgroup, where most of the electrostatic charge is concentrated, and a nonpolar butyl chain. The polar imidazolium ring of cations and anions could connect each other to form the polar domain, while the nonpolar butyl chains may aggregate to form the nonpolar domain. ${ }^{38-41}$ Quitevis and co-workers proposed a schematic representation that provides a reasonable pattern to visualize the nanostructuring present in the ionic liquids. ${ }^{24-28}$ It is not surprising that because of the strong electrostatic interactions among cations and anions of $[\mathrm{bmim}]\left[\mathrm{PF}_{6}\right]$ the structure of polar domains is more closely packed than that of nonpolar domains in which the interaction is from van der Waals force between nonpolar butyl chains within $[\mathrm{bmim}]\left[\mathrm{PF}_{6}\right]$. Therefore, as shown in Figure 3, since C153 is a neutral molecule and there is

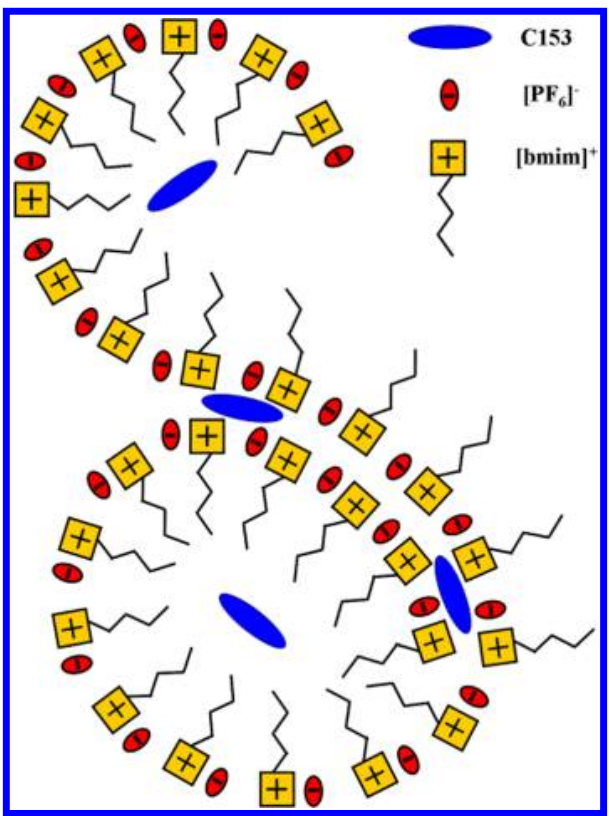

Figure 3. Schematic representation of the $\mathrm{C} 153$ probe molecules in structural heterogeneous ionic liquid $[\mathrm{bmim}]\left[\mathrm{PF}_{6}\right]$ with incompact nonpolar and compact polar domains.

no specific solute-solvent interactions between $\mathrm{C} 153$ and $[\mathrm{bmim}]\left[\mathrm{PF}_{6}\right], \mathrm{C} 153$ could disperse into incompact nonpolar and compact polar domains of $[\mathrm{bmim}]\left[\mathrm{PF}_{6}\right]$. The two different time constants observed from the rotational dynamics of C153 could correspond to such kinds of two typical microenvironments. The fast composition of $\mathrm{C} 153$ rotational dynamics is attributed to the incompact nonpolar domain in neat $[\mathrm{bmim}]\left[\mathrm{PF}_{6}\right]$, in which the microenvironment is built up by the aggregation of butyl chains of $[\mathrm{bmim}]\left[\mathrm{PF}_{6}\right]$ in a relatively loose microstructure, leading to a lower microviscosity, where the molecular probe $\mathrm{C} 153$ is easier to rotate. The slow composition of $\mathrm{C} 153$ rotational dynamics is accordingly contributed from the compact polar domain with more closely packed microstructure connected by imidazolium ring cations and anions, resulting in a relatively higher microviscosity; therefore, the rotation of $\mathrm{C} 153$ is more confined and becomes slow. Since C153 is considered to be an ideal probe related to nonspecific solute-solvent interactions in many RTIL

Table 2. Rotational Relaxation Parameters for C153 in $[\mathrm{bmim}]\left[\mathrm{PF}_{6}\right]$ and TEGDME Mixtures

\begin{tabular}{|c|c|c|c|c|c|c|c|c|}
\hline \multirow[b]{2}{*}{ TEGDME mole fraction } & \multicolumn{5}{|c|}{ fitting results ${ }^{a}$} & \multicolumn{3}{|c|}{ stretched exponential fitting ${ }^{b}$} \\
\hline & $A_{1}$ & $\tau_{1}(\mathrm{~ns})$ & $A_{2}$ & $\tau_{2}(\mathrm{~ns})$ & $\tau_{\mathrm{r}}^{c}(\mathrm{~ns})$ & $\tau(\mathrm{ns})$ & $\beta$ & $\tau_{\mathrm{r}}^{d}(\mathrm{~ns})$ \\
\hline 0 & 0.49 & 0.32 & 0.51 & 4.90 & 2.66 & 2.13 & 0.70 & 2.69 \\
\hline 0.1 & 0.39 & 0.39 & 0.61 & 4.45 & 2.87 & 2.19 & 0.67 & 2.90 \\
\hline 0.2 & 0.41 & 0.48 & 0.59 & 3.90 & 2.50 & 2.04 & 0.68 & 2.66 \\
\hline 0.3 & 0.50 & 0.65 & 0.50 & 3.61 & 2.13 & 1.81 & 0.69 & 2.32 \\
\hline 0.4 & 0.45 & 0.73 & 0.55 & 2.88 & 1.91 & 1.56 & 0.70 & 1.97 \\
\hline 0.5 & 0.50 & 0.77 & 0.50 & 2.64 & 1.71 & 1.41 & 0.72 & 1.74 \\
\hline 0.6 & 0.65 & 0.76 & 0.35 & 2.13 & 1.24 & 1.16 & 0.83 & 1.28 \\
\hline 0.7 & 0.65 & 0.74 & 0.35 & 1.63 & 1.05 & 0.98 & 0.90 & 1.03 \\
\hline 0.8 & 0.74 & 0.70 & 0.26 & 1.19 & 0.83 & 0.84 & 0.95 & 0.86 \\
\hline 0.9 & & 0.63 & & 0.63 & 0.63 & 0.64 & 0.99 & 0.64 \\
\hline 1 & & 0.46 & & 0.46 & 0.46 & 0.46 & 1.00 & 0.46 \\
\hline
\end{tabular}

${ }^{a}$ Exponential fitting using eq $3 .{ }^{b}$ Stretched exponential fitting using the function $r(t)=r_{0} \exp [-(t / \tau)]^{\beta}{ }^{66}{ }^{c}$ The average rotation time from biexponential fitting using eq $4, A_{i}=a_{i} / \sum_{i=1}^{2} a_{i}, \sum_{i=1}^{2} A_{i}=1$. ${ }^{d}$ The rotation time from stretched exponential fitting using $\left\langle\tau_{\mathrm{r}}\right\rangle=\tau \Gamma\left(\beta^{-1}\right) / \beta$, where $\Gamma$ is the gamma fuction. ${ }^{6}$ 
systems, ${ }^{17,52,53,58}$ the microviscosity around C153 in ionic liquid mainly affects the rotation behaviors and leads to the different rotational relaxation times. Therefore, it is important to investigate the changes of microviscosity in different structural domains of $[\mathrm{bmim}]\left[\mathrm{PF}_{6}\right]$ before and after adding cosolvent TEGDME at different fractions by obtaining different time constants from the fitted anisotropy decay of probe molecules and further estimate the average rotational relaxation time for getting a general insight of the microviscosity changes in the mixtures.

Figure 4 shows the fast component of $\mathrm{C} 153$ rotation time correlated with different TEGDME mole fractions in [bmim]-

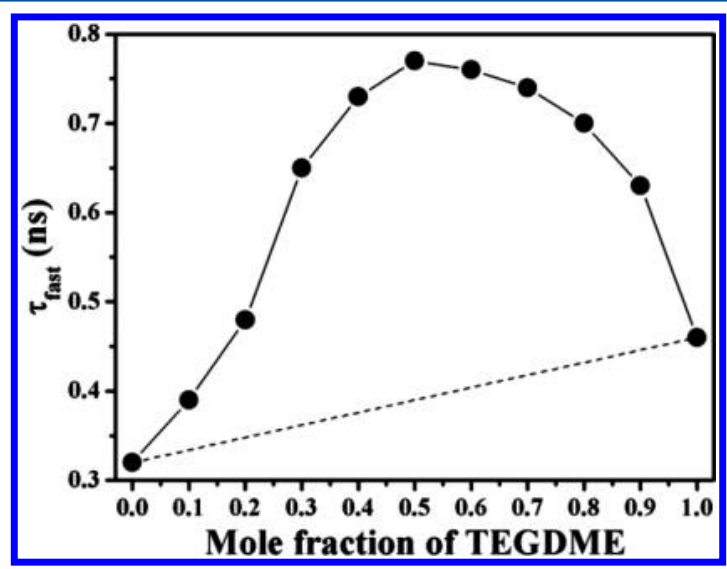

Figure 4. Fast component of $\mathrm{C} 153$ rotation time correlated with different TEGDME mole fractions in $[\mathrm{bmim}]\left[\mathrm{PF}_{6}\right]$ and TEGDME mixtures.

$\left[\mathrm{PF}_{6}\right]$ and TEGDME mixtures. It is found that, with the addition of TEGDME, the value of the fast rotation time constant $\left(\tau_{1}\right)$ in $[\mathrm{bmim}]\left[\mathrm{PF}_{6}\right]$ and TEGDME mixtures increases first and reaches a maximum when the TEGDME mole fraction reaches about 0.5 , then decreases with further addition of TEGDME. Since the fast decay of C153 rotational dynamics is correlated with the microviscosity of the incompact domain within the mixtures, it is reasonable that by gradually adding TEGDME the relatively loose microenvironment of the incompact domain in ionic liquid becomes a little tighter at first with increased microviscosity because of the van der Waals interaction between nonpolar TEGDME and butyl chains of $[\mathrm{bmim}]\left[\mathrm{PF}_{6}\right]$, and then loosens again with further addition of the cosolvent because the heterogeneous microstructure within ionic liquid is totally broken by mixing with a large amount of TEGDME, resulting in the decrease of microviscosity. An obvious fact is also revealed by Figure 4 that, in all intermediate mole fractions of the mixtures, the value of the fast rotation time constant $\left(\tau_{1}\right)$ is always larger than that in neat $[\mathrm{bmim}]\left[\mathrm{PF}_{6}\right]$, which implies that the microviscosity of the incompact domain in ionic liquid is enhanced due to the mixing of TEGDME, reasonably resulting from the van der Waals interaction between nonpolar TEGDME and butyl chains of $[\mathrm{bmim}]\left[\mathrm{PF}_{6}\right]$.

Regarding the values of the slow time constant $\left(\tau_{2}\right)$ obtained from the C153 rotational dynamics measurements, it is found that $\tau_{2}$ linearly decreases and is well correlated with the mole fraction of TEGDME in the mixtures, as shown in Figure 5. As the slow decay of $\mathrm{C} 153$ rotational dynamics is related to the microviscosity of the compact domain of the mixtures, it is possible that the interactions between the two neat

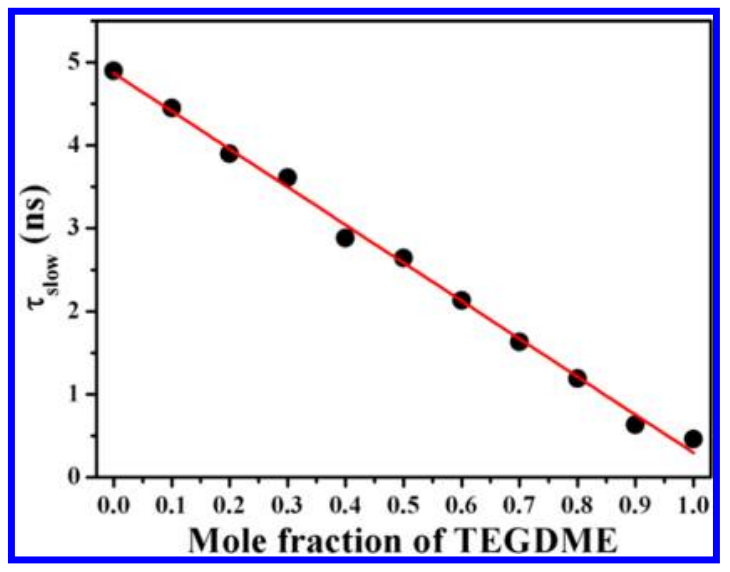

Figure 5. Slow anisotropy time constants of $\mathrm{C} 153$ in $[\mathrm{bmim}]\left[\mathrm{PF}_{6}\right]$ and TEGDME mixtures with different TEGDME mole fractions.

compositions of the mixtures destroy the structure of the compact domain which is built by imidazolium ring cations and anions and lead to the decrease of microviscosity. Many groups studied the effects of the cosolvents in ionic liquids through testing the rotational dynamics of $\mathrm{C} 153$, and these investigations showed that the presence of cosolvent molecules reduced the electrostatic attraction between ions through solvent-solvent interactions like hydrogen bonds, resulting in a decrease in local viscosity, ${ }^{50-54}$ and therefore, the slow rotation of $\mathrm{C} 153$ in ionic liquid becomes fast. In our case, we observe a similar effect by investigating the slow component of C153 rotational dynamics.

Compared to the cosolvent such as poly(ethylene glycol) (PEG) or tetraethylene glycol (TEG) which mainly affects the polar domains of ionic liquid through hydrogen-bonding interactions with the cations and anions, ${ }^{55-57}$ the nonpolar cosolvent TEGDME without the presence of a hydroxyl group could efficiently affect the nonpolar domains and the polar domains of $[\mathrm{bmim}]\left[\mathrm{PF}_{6}\right]$. As TEGDME molecules have a certain length nonpolar chain, they could change the chain conformation to arrange themselves into the incompact nonpolar domain of $[\mathrm{bmim}]\left[\mathrm{PF}_{6}\right]$ and also interact with the cations of the compact polar domain through the weak hydrogen-bonding interactions between the oxygen of the ether bond in TEGDME and the imidazolium ring proton at the same time. In the incompact nonpolar domains, TEGDME and $[\mathrm{bmim}]\left[\mathrm{PF}_{6}\right]$ interact with each other through the packing and stacking effects by van der Waals interaction between the TEGDME molecule and the butyl chain of ionic liquid. When the TEGDME mole fraction is in the region from 0 to 0.5 and the mixture is in the ionic liquid enrichment phase, the heterogeneous nature with two types of structural domains by $[\mathrm{bmim}]\left[\mathrm{PF}_{6}\right]$ mainly remains within the mixtures (see also the results of the departure between $\mathrm{C} 153$ average rotation time from experiment and from calculated bulk viscosity in Figure 6). The packing and stacking effects of the TEGDME molecular chain gradually make the incompact domain more and more dense with the TEGDME mole fraction increasing from 0 to 0.5 . This strengthening effect causes the microviscosity of incompact domains in the mixtures to increase, becomes more pronounced when the mole fraction of TEGDME is larger than 0.2 , and reaches a maximum when the TEGDME mole fraction is up to 0.5 , as shown in Figure 4. When the mole fraction of TEGDME is further increased from 0.5 to 1 , while the mixture is in the TEGDME enrichment 


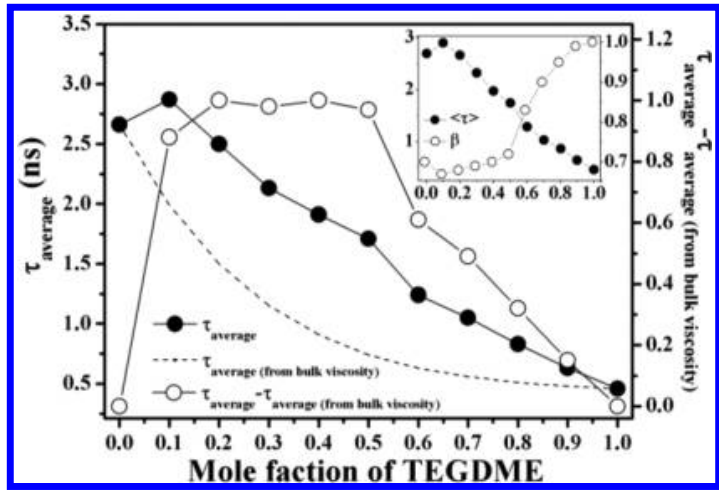

Figure 6. The experimental average rotation time of $\mathrm{C} 153(0)$ in $[\mathrm{bmim}]\left[\mathrm{PF}_{6}\right]-$ TEGDME mixtures with different TEGDME mole fractions. The dashed curve shows the $\mathrm{C} 153$ average rotation time calculated from the bulk viscosity of the mixtures. The departure $(O)$ between experimental average rotation time and calculated average rotation time estimated from bulk viscosity. The inset shows the C153 rotation time obtained from the stretched exponential fitting $(\bullet$, left axis) and the fitted parameter $\beta(\mathrm{O}$, right axis) as a function of TEGDME mole fraction.

phase, the heterogeneous structure of the mixture is gradually destroyed by adding more and more TEGDME. It is found that there is only one type of microenvironment in the mixture when the TEGDME mole fraction reaches about 0.9 , while a single exponential fitting of the $\mathrm{C} 153$ rotational decay is obtained (see Table 2), suggesting that, in high TEGDME mole fractions, the difference of compact and incompact domains within the mixture mostly disappears, and the mixture becomes more homogeneous. Since the heterogeneous structure (Figure 3) disappears when the TEGDME mole fraction is larger than 0.5 of the mixtures, the gradually increased strengthening effect in the incompact domain with the TEGDME fraction from 0 to 0.5 is weakened, which leads to the microviscosity decrease, as shown in Figure 4.

As shown in Table 2, the rotational relaxation time of $\mathrm{C} 153$ in neat TEGDME is about $0.46 \mathrm{~ns}$ in our measurement. When the TEGDME mole fraction is around 0.9, the C153 rotational relaxation time is $0.63 \mathrm{~ns}$, which is a little slower than that in the neat TEGDME, indicating that a small amount of [bmim $]\left[\mathrm{PF}_{6}\right]$ could possibly change the microenvironment of neat TEGDME to be more compact. The inter/intramolecular interactions in neat TEGDME molecules are mainly van der Waals force which is weaker than the systems containing strong hydrogen-bonding or electrostatic interactions. When the neat TEGDME mixes with $[\mathrm{bmim}]\left[\mathrm{PF}_{6}\right]$, the hydrogen-bonding interactions between the oxygen of ether bond in TEGDME and the imidazolium ring proton as well as the interactions between ions of ionic liquid cause a more compact structure, which results in the slower rotation of $\mathrm{C} 153$ and the higher microviscosity compared to the neat TEGDME. Judging from the values of the fast time constant $\left(\tau_{1}\right)$ as shown in Table 2 and Figure 4, it is found that the microviscosity enhancement is more obvious when adding a slight amount of $[\mathrm{bmim}]\left[\mathrm{PF}_{6}\right]$ into TEGDME with a mole fraction of TEGDME from 1 to 0.9 , compared to that from 0 to 0.1 . Therefore, it is concluded that, once a small amount of TEGDME is added into [bmim $]\left[\mathrm{PF}_{6}\right]$, the microviscosity enhancement effect is mainly due to van der Waals interactions which is reasonably weaker than the hydrogen-bonding interactions when adding a small amount of ionic liquid into TEGDME. In one word, the microviscosity of incompact domains in neat $[\mathrm{bmim}]\left[\mathrm{PF}_{6}\right]$ and neat TEGDME is enhanced by the strengthening effect in their mixtures through the van der Waals and hydrogen-bonding interactions, and becomes most pronounced when the mole fraction of the two neat compositions is about equal.

In the compact polar domains of the mixtures, the main interactions are the Coulombic and hydrogen-bonding interactions between cations and anions in ionic liquid as well as the hydrogen-bonding effects between the oxygen of the ether bond in TEGDME and the imidazolium ring proton. TEGDME molecules could form new hydrogen bonds with ionic liquid and insert into strong Coulombic interaction areas between cations and anions, which screens the electrostatic interactions of ions in compact domains of the mixtures. This force loosens the compact microstructure around the molecular probe $\mathrm{C} 153$, and makes an easier microenvironment for the C153 rotation. Therefore, as shown in Figure 5, with the gradual addition of TEGDME into $[\mathrm{bmim}]\left[\mathrm{PF}_{6}\right]$, the value of the slow time constant $\left(\tau_{2}\right)$ of $\mathrm{C} 153$ decreases with a good consistency with the increasing mole fraction of TEGDME, showing a linearly decreasing effect of the microviscosity within the compact domains of the mixtures.

To further understand the microviscosity changes in $[\mathrm{bmim}]\left[\mathrm{PF}_{6}\right]$ and TEGDME mixtures with different mole fractions, the experimental average rotational relaxation time $\left(\tau_{\text {average }}\right)$ of $\mathrm{C} 153$ is further considered. Figure 6 shows the average rotation time of $\mathrm{C} 153$ in $\left[\mathrm{bmim}^{2}\left[\mathrm{PF}_{6}\right]-\mathrm{TEGDME}\right.$ mixtures with different TEGDME mole fractions. The calculated average rotation time of $\mathrm{C} 153$ from the bulk viscosity is also obtained by estimating the bulk viscosity of the mixtures and the linear correlation between the bulk viscosity and the $\mathrm{C} 153$ experimental average rotation time fixed by neat ionic liquid and TEGDME according to the Debye-StokesEinstein equation. ${ }^{52-54}$ The bulk viscosities of the neat $[$ bmim $]\left[\mathrm{PF}_{6}\right](\sim 300 \mathrm{cP})$ and TEGDME $\left(3.313 \mathrm{cP}^{67}\right)$ are used to calculate the bulk viscosity of the mixtures by using the equation of $\ln \eta_{\text {mix }}=\sum_{i=1}^{2} \omega_{i} \ln \eta_{i}{ }^{68}$ where $\eta_{i}$ and $\omega_{i}$ represent the bulk viscosity and weight component of the individual constituent, respectively. The departure between experimental average rotation time and calculated average rotation time estimated from the bulk viscosity of $\mathrm{C} 153$ reflects the difference between the microviscosity and viscosity caused by the heterogeneous nature of the mixtures from the new interaction between ionic liquid and TEGDME, such as van der Waals and hydrogen bonding interactions. ${ }^{43}$

With the gradual addition of TEGDME, the experimental average rotation time of $\mathrm{C} 153$ in the mixtures is found to increase first and then decrease, as shown in Figure 6. Especially the obtained average rotational relaxation time is $2.87 \mathrm{~ns}$ when the TEGDME mole fraction is 0.1 of the mixture, which is unexpectedly a little slower than that in neat $[\mathrm{bmim}]\left[\mathrm{PF}_{6}\right]$ $(2.66 \mathrm{~ns})$. It is possible that in the high $[\mathrm{bmim}]\left[\mathrm{PF}_{6}\right]$ enrichment phase of the mixture the enhancement effect of microviscosity by the interactions within the nonpolar domains between TEGDME and ionic liquid could compensate the loss of Coulombic interaction in the polar domains and even slow down the rotation of $\mathrm{C} 153$. In Figure 6, it is found that, in the whole TEGDME mole fraction range of the mixtures, the value of the observed $\mathrm{C} 153$ average rotation time is larger than that calculated from the bulk viscosity, indicating that the new interactions (such as van der Waals and hydrogen-bonding interactions, as well as screening effects of the Coulombic interactions) in $[\mathrm{bmim}]\left[\mathrm{PF}_{6}\right]$ and TEGDME mixtures are 
involved, which is not considered in the calculated bulk viscosity condition. From the values of the departure between experimental and calculated average rotation time of the mixtures, it is found that the heterogeneous structure of the mixtures obviously remains in the ionic liquid enrichment phase and gradually is destroyed by adding more TEGDME. Although the biexponential fitting is found to be somewhat better than the stretched exponential fitting, the value of the $\mathrm{C} 153$ average rotation time from exponential fitting is very similar to the rotation time from stretched exponential fitting (as shown in Table 2 and Figure 6). The departure results are in agreement with the values of $\beta(0 \leq \beta \leq 1)$ obtained from the stretched exponential fitting, as shown in the inset of Figure 6 , which typically reflects the heterogeneity of the cosolvent mixture, as the smaller value of $\beta$ represents the more significant heterogeneity. ${ }^{16}$ Therefore, as the TEGDME molecules interact with the ionic liquid $[\mathrm{bmim}]\left[\mathrm{PF}_{6}\right]$ within the nonpolar incompact and polar compact domains, the microviscosity of the mixtures is enhanced in contrast with both of the two neat compositions when the TEGDME mole fraction is 0.1 and the heterogeneous structure mainly remains in the ionic liquid enrichment phase of the mixture.

3.3. Fluorescence Emission Behavior of Microviscosity Probe BPP. We have measured the microviscosity of [bmim $]\left[\mathrm{PF}_{6}\right]$ and TEGDME mixtures by the rotational dynamics of $\mathrm{C} 153$, and in order to further confirm the microviscosity enhancement effects in this mixture, as a complementary experiment, we perform the steady-state fluorescence emission experiments of a microviscosity probe BPP which is especially sensitive in the heterogeneous system. $^{55-57,59-62,69-71} 1,3-\mathrm{Bis}$ (1-pyrenyl)propane (BPP) (Scheme 1) is a well-established fluorescent probe which can be employed to detect the microviscosity by measuring the excimer emission band located in about the 450-500 nm region in fluorescence emission spectra. In a low-viscous solvent, the two pyrene units of BPP easily fold together to form an intramolecular excimer, and the emission spectra of these compounds exhibit a usual structured monomer fluorescence band and a broad structureless excimer fluorescence band. As the microviscosity of the environment increases, the efficiency of the excimer formation decreases and a corresponding reduction in the intensity of the excimer band is observed. From such a scenario, the excimer to monomer emission intensity ratio $\left(I_{\mathrm{E}} / I_{\mathrm{M}}\right)$ of BPP can be used to measure the microviscosity. In our case, BPP is chosen due to its several advantages as follows. First, BPP is a neutral molecule, and previous studies have shown that the observed results from BPP are mainly caused by the solvent-solvent interactions in the $[\mathrm{bmim}]\left[\mathrm{PF}_{6}\right]-\mathrm{TEG}$ and $[\mathrm{bmim}]\left[\mathrm{PF}_{6}\right]-\mathrm{PEG}$ systems which are quite similar to our $\left[\mathrm{bmim}^{2}\left[\mathrm{PF}_{6}\right]-\mathrm{TEGDME}\right.$ system. ${ }^{55-57}$ Second, BPP is very sensitive to the microviscosity enhancement in the heterogeneous $[\mathrm{bmim}]\left[\mathrm{PF}_{6}\right]$ and $\mathrm{PEG}$ mixtures, even though the bulk viscosity does not increase significantly. ${ }^{55}$ Consequently, we can further clarify the microviscosity enhancement effects in our system through studying the steady-state emission spectra of BPP. Third, BPP is not very sensitive to the polarity of the media; therefore, the influences of the polarity in our system are mainly neglected. ${ }^{61}$ Fourth, since the solubility of BPP in water is extremely low, we can mostly eliminate the effects of water in our experiment if there are any. 60

Figure 7 shows the steady-state emission spectra for BPP dissolved in the mixtures of $[\mathrm{bmim}]\left[\mathrm{PF}_{6}\right]$ and TEGDME. It is

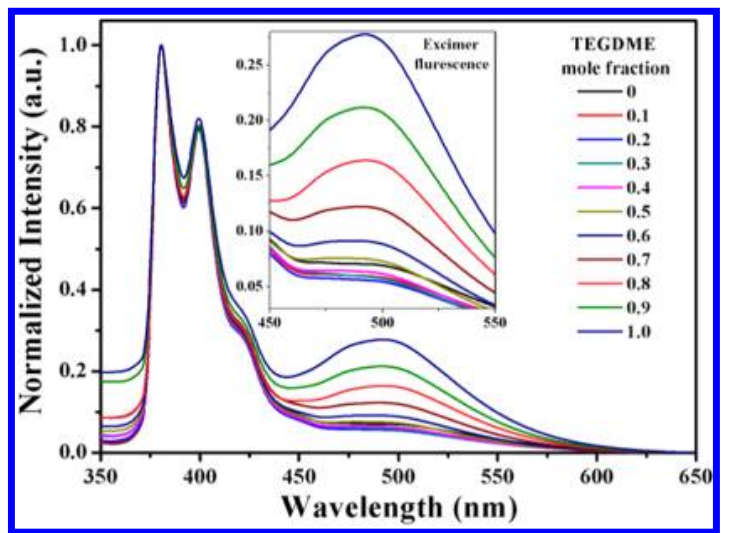

Figure 7. Steady-state fluorescence emission spectra normalized to the peak of the monomer fluorescence band $\left(I_{\mathrm{M}(380 \mathrm{~nm})}=1.00\right)$ for about 1 $\mu \mathrm{M}$ BPP in $[\mathrm{bmim}]\left[\mathrm{PF}_{6}\right]$ and TEGDME mixtures; excitation wavelength: $330 \mathrm{~nm}$. The inset shows the excimer fluorescence band $\left(I_{\mathrm{E}(490 \mathrm{~nm})}\right)$.

found that, when the TEGDME mole fraction is below 0.5 , the excimer peak of BPP fluorescence is not obvious, whereas, when the TEGDME mole fraction is above 0.5, the excimer peak of BPP is clearly observed and becomes much more pronounced with further addition of TEGDME. It is unexpected that, when the TEGDME mole fraction is from 0.1 to 0.4 , the relative amount of excimer emission is slightly less than that in neat $[\mathrm{bmim}]\left[\mathrm{PF}_{6}\right]$, as shown in the inset of Figure 7 , indicating that, in this $[\mathrm{bmim}]\left[\mathrm{PF}_{6}\right]$ enrichment phase condition, two terminal pyrenyl moieties of the probe BPP are harder to fold together compared to that in neat ionic liquid. The observed values of the excimer-to-monomer emission intensity ratio $I_{\mathrm{E}} / I_{\mathrm{M}}$ (obs) of BPP under ambient conditions in the $[\mathrm{bmim}]\left[\mathrm{PF}_{6}\right]$ and TEGDME system are shown in Figure 8.

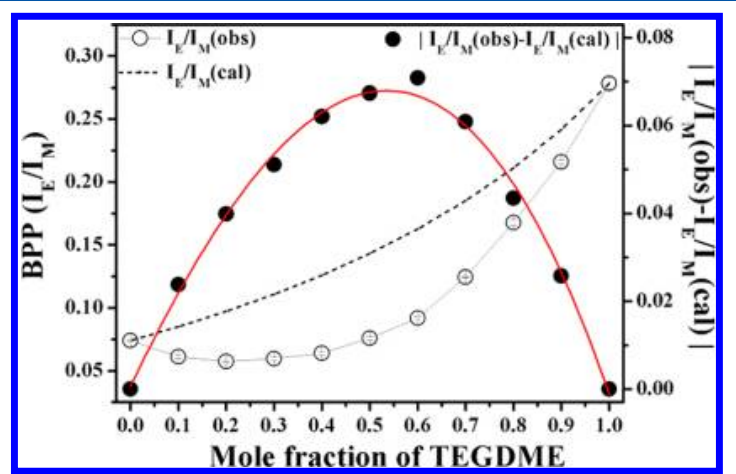

Figure 8. Experimentally observed $I_{\mathrm{E}} / I_{\mathrm{M}}$ (obs) (O) of BPP in the [bmim $]\left[\mathrm{PF}_{6}\right]$ and TEGDME mixtures. All fluorescence emission spectra of BPP in the mixtures were averaged from three time measurements. The dashed curve shows the TEGDME mole fraction weighted ideal calculated BPP $I_{\mathrm{E}} / I_{\mathrm{M}}(\mathrm{cal})$ according to eq 5 . The departure between the experimental $I_{\mathrm{E}} / I_{\mathrm{M}}$ (obs) and calculated $I_{\mathrm{E}} /$ $I_{\mathrm{M}}(\mathrm{cal})$ values of BPP is presented alongside $(\bullet)$. The red profile shown is only a guide to the eye.

Generally, it is expected that the value of $I_{\mathrm{E}} / I_{\mathrm{M}}$ (obs) would monotonically increase as the less viscous TEGDME is added to the more viscous $[\mathrm{bmim}]\left[\mathrm{PF}_{6}\right]$, but our result shows that, with the addition of TEGDME to $[\mathrm{bmim}]\left[\mathrm{PF}_{6}\right]$, the $I_{\mathrm{E}} / I_{\mathrm{M}}(\mathrm{obs})$ value of BPP decreases first and then reaches a minimum with the mole fraction of TEGDME around 0.2, and finally increases to its value in neat TEGDME. Importantly, the $I_{\mathrm{E}} / I_{\mathrm{M}}$ (obs) 
shows a smaller value than that in neat $\left[\mathrm{bmim}^{\mathrm{b}}\right]\left[\mathrm{PF}_{6}\right]$ and TEGDME when the mole fraction of TEGDME is in the region between 0.1 and 0.4 . Since the value of BPP $I_{E} / I_{M}$ (obs) is correlated with the microviscosity, it is found that the microviscosity of the mixture is higher than both of the neat compositions with the TEGDME mole fraction from 0.1 to 0.4 , and in the TEGDME enrichment phase when the mole fraction of TEGDME is above 0.5 , the microviscosity decreases with the addition of TEGDME. Such a microviscosity enhancement effect is observed especially in the ionic liquid enrichment phase because of some strengthening effect in the mixture, such as the packing and stacking interaction between butyl chains of [bmim $]\left[\mathrm{PF}_{6}\right]$ and TEGDME molecular chains around the BPP probe molecules. Similar behavior is also seen from the average rotational relaxation time $\left(\tau_{\text {average }}\right)$ of $\mathrm{C} 153$, as shown in Figure 6.

In order to further determine the degree of the microviscosity enhancement effects in $[\mathrm{bmim}]\left[\mathrm{PF}_{6}\right]$ and TEGDME mixtures, we investigate the departure between the experimental observed value and ideal additive calculated value of $I_{\mathrm{E}} /$ $I_{\mathrm{M}}\left(\left|I_{\mathrm{E}} / I_{\mathrm{M}}(\mathrm{obs})-I_{\mathrm{E}} / I_{\mathrm{M}}(\mathrm{cal})\right|\right)$, which could reflect the difference between the observed microviscosity and that in calculation condition without considering extra special interactions in the mixture. As shown in Figure 8, the ideal additive calculated $I_{\mathrm{E}} / I_{\mathrm{M}}(\mathrm{cal})$ of BPP in the $[\mathrm{bmim}]\left[\mathrm{PF}_{6}\right]$ and TEGDME mixtures is calculated using eq $5^{72}$

$$
\begin{aligned}
& \left(\frac{I_{\mathrm{E}}}{I_{\mathrm{M}}}\right)_{\mathrm{cal}}= \\
& \frac{\left(I_{\mathrm{E},[\mathrm{bmim}]\left[\mathrm{PF}_{6}\right]} \times \chi_{[\mathrm{bmim}]\left[\mathrm{PF}_{6}\right]}\right)+\left(I_{\mathrm{E}, \mathrm{TEGDME}} \times \chi_{\mathrm{TEGDME}}\right)}{\left(I_{\mathrm{M},[\mathrm{bmim}]\left[\mathrm{PF}_{6}\right]} \times \chi_{[\mathrm{bmim}]\left[\mathrm{PF}_{6}\right]}\right)+\left(I_{\mathrm{M}, \mathrm{TEGDME}} \times \chi_{\mathrm{TEGDME}}\right)}
\end{aligned}
$$

in which $I_{\mathrm{E}}$ and $I_{\mathrm{M}}$ values were measured in neat $[\mathrm{bmim}]\left[\mathrm{PF}_{6}\right]$ and TEGDME under identical experimental conditions and $I_{\mathrm{E}} /$ $I_{\mathrm{M}}(\mathrm{cal})$ for $[\mathrm{bmim}]\left[\mathrm{PF}_{6}\right]$ and TEGDME mixtures were calculated using the bulk mole fraction, $X_{i}$, for each component. The result of ideal additive behavior is depicted using the dashed curve in Figure 8. It is found that all of the values of $I_{\mathrm{E}} /$ $I_{\mathrm{M}}(\mathrm{obs})$ of BPP are smaller than the corresponding $I_{\mathrm{E}} / I_{\mathrm{M}}(\mathrm{cal})$ across all mole fractions of $\left[\mathrm{bmim}^{2}\left[\mathrm{PF}_{6}\right]\right.$ and TEGDME mixtures, which clearly indicates that BPP is facing a more viscous microenvironment than predicted $\left(I_{\mathrm{E}} / I_{\mathrm{M}}(\mathrm{cal})\right)$. This unusual behavior measured by the value of $I_{\mathrm{E}} / I_{\mathrm{M}}$ indicates that the microviscosity of the mixtures could be enhanced by the molecular interactions between $[\mathrm{bmim}]\left[\mathrm{PF}_{6}\right]$ and TEGDME evidently. Moreover, the deviation of the observed and calculated $I_{\mathrm{E}} / I_{\mathrm{M}}$ values reaches a maximum near the equimolar ratio of $[\mathrm{bmim}]\left[\mathrm{PF}_{6}\right]$ and TEGDME. Therefore, it is concluded that the microviscosity of the mixtures is enhanced, and with about the equal mole fraction of the two neat compositions the degree of the enhancement is most significant, which is also in agreement with the results from the fast time constant $\left(\tau_{1}\right)$ of $\mathrm{C} 153$ rotational dynamics in these mixtures. Once again, it is found that the microviscosity enhancement within the mixtures is possibly caused by the strengthening effects between $[\mathrm{bmim}]\left[\mathrm{PF}_{6}\right]$ and TEGDME molecules.

The difference between the bulk viscosity and microviscosity obtained by investigating the average rotation time of C153 as shown in Figure 6 and the departure between the experimental observed and calculated microviscosity from the $I_{\mathrm{E}} / I_{\mathrm{M}}$ value of $\mathrm{BPP}$ as shown in Figure 8 prove that there are some extra special strengthening interactions between $[\mathrm{bmim}]\left[\mathrm{PF}_{6}\right]$ and TEGDME molecules in their mixture with heterogeneity. This strengthening effect possibly caused by the molecular packing and stacking interactions through van der Waals force in ionic liquid enrichment phase, and the hydrogen-bonding interactions in TEGDME enrichment phase of the mixture, which shows a maximum when the mole fraction of the two neat compositions is about equal by investigating the fast time constant $\left(\tau_{1}\right)$ of $\mathrm{C} 153$ rotational dynamics (Figure 4) and the value of $\left|I_{\mathrm{E}} / I_{\mathrm{M}}(\mathrm{obs})-I_{\mathrm{E}} / I_{\mathrm{M}}(\mathrm{cal})\right|$ of $\mathrm{BPP}$ (Figure 8 ). Furthermore, from the results of measured microviscosity by $I_{\mathrm{E}} / I_{\mathrm{M}}$ (obs) of BPP in the case of TEGDME mole fraction from 0.1 to 0.4 (Figure 8 ) and average rotational relaxation time $\left(\tau_{\text {average }}\right)$ of $\mathrm{C} 153$ rotational dynamics when the TEGDME mole fraction is 0.1 (Figure 6), it is concluded that in the ionic liquid enrichment phase of the $[\mathrm{bmim}]\left[\mathrm{PF}_{6}\right]$ and TEGDME mixture the molecular strengthening interactions could compensate the loss of Coulombic interaction and result in the larger microviscosity than those of the two neat individual compositions.

\section{CONCLUSIONS}

We have performed measurements of the rotational dynamics of C153 molecules in a completely compatible hybrid system based on room temperature ionic liquid $[\mathrm{bmim}]\left[\mathrm{PF}_{6}\right]$ and TEGDME to detect the local viscosity enhancement of the microenvironment surrounding the probe molecules. The microviscosity enhancement is also investigated by a microviscosity probe $\mathrm{BPP}$ through steady-state fluorescence spectroscopy. Due to the heterogeneous nature of ionic liquid, it is found that the $\mathrm{C} 153$ probe is experiencing two types of domains with incompact and compact structures in [bmim]$\left[\mathrm{PF}_{6}\right]$. With the addition of TEGDME, the microviscosity of the incompact domain in ionic liquid is increased especially when the TEGDME mole fraction is about 0.5, while the microviscosity of the compact domain is linearly decreased. In the high ionic liquid enrichment phase, the excited C153 molecules show relatively slower rotational dynamics determined by the average rotation time and the excimer-tomonomer fluorescence emission intensity ratio $\left(I_{\mathrm{E}} / I_{\mathrm{M}}\right)$ of BPP is lower than those in both neat $[\mathrm{bmim}]\left[\mathrm{PF}_{6}\right]$ and TEGDME, indicating that independently both of the two probe molecules are unexpectedly facing a more viscous microenvironment. Besides the microviscosity enhancement determined from the fast time constant of $\mathrm{C} 153$ rotational dynamics, the enhanced microviscosity judged from $\left|I_{\mathrm{E}} / I_{\mathrm{M}}(\mathrm{obs})-I_{\mathrm{E}} / I_{\mathrm{M}}(\mathrm{cal})\right|$ of $\mathrm{BPP}$ also shows that this effect is more obvious when the mole fraction of $[\mathrm{bmim}]\left[\mathrm{PF}_{6}\right]$ and TEGDME is about equal in the mixtures. The strengthening effects caused by the interactions of the TEGDME molecules with a certain chain length and heterogeneous structural ionic liquid $[\mathrm{bmim}]\left[\mathrm{PF}_{6}\right]$ are proposed to interpret the unusual microviscosity enhancement in our system.

\section{AUTHOR INFORMATION}

\section{Corresponding Author}

*E-mail: andong@iccas.ac.cn (A.X.); guoqj@iccas.ac.cn (Q.G.).

\section{Notes}

The authors declare no competing financial interest. 


\section{ACKNOWLEDGMENTS}

This work was financially supported by NSFC, 973 Programs and Chinese Academy of Sciences. S.V. thanks CAS for support from the CAS Research Fellowship for International Young Researchers.

\section{REFERENCES}

(1) Seddon, K. R. Nat. Mater. 2003, 2 (6), 363-365.

(2) Welton, T. Chem. Rev. 1999, 99 (8), 2071-2083.

(3) Dupont, J.; de Souza, R. F.; Suarez, P. A. Z. Chem. Rev. 2002, 102 (10), 3667-3691.

(4) Huddleston, J. G.; Willauer, H. D.; Swatloski, R. P.; Visser, A. E.; Rogers, R. D. Chem. Commun. 1998, 16, 1765-1766.

(5) Dickinson, E.; Williams, M. E.; Hendrickson, S. M.; Masui, H.; Murray, R. W. J. Am. Chem. Soc. 1999, 121 (4), 613-616.

(6) Rogers, R. D.; Seddon, K. R. Science 2003, 302 (5646), 792-793.

(7) Parvulescu, V. I.; Hardacre, C. Chem. Rev. 2007, 107 (6), 26152665.

(8) Hubbard, C. D.; Illner, P.; van Eldik, R. Chem. Soc. Rev. 2011, 40 (1), 272-290.

(9) Blanchard, L. A.; Hancu, D.; Beckman, E. J.; Brennecke, J. F. Nature 1999, 399 (6731), 28-29.

(10) Cadena, C.; Anthony, J. L.; Shah, J. K.; Morrow, T. I.; Brennecke, J. F.; Maginn, E. J. J. Am. Chem. Soc. 2004, 126 (16), 5300-5308.

(11) Paul, A.; Mandal, P. K.; Samanta, A. J. Phys. Chem. B 2005, 109 (18), 9148-9153.

(12) Karmakar, R.; Samanta, A. J. Phys. Chem. A 2002, 106 (28), 6670-6675.

(13) Karmakar, R.; Samanta, A. J. Phys. Chem. A 2002, 106 (18), 4447-4452.

(14) Karmakar, R.; Samanta, A. J. Phys. Chem. A 2003, 107 (38), $7340-7346$

(15) Saha, S.; Mandal, P. K.; Samanta, A. Phys. Chem. Chem. Phys. 2004, 6 (12), 3106-3110.

(16) Jin, H.; Li, X.; Maroncelli, M. J. Phys. Chem. B 2007, 111 (48), 13473-13478.

(17) Jin, H.; Baker, G. A.; Arzhantsev, S.; Dong, J.; Maroncelli, M. J. Phys. Chem. B 2007, 111 (25), 7291-7302.

(18) Ingram, J. A.; Moog, R. S.; Ito, N.; Biswas, R.; Maroncelli, M. J. Phys. Chem. B 2003, 107 (24), 5926-5932.

(19) Ito, N.; Arzhantsev, S.; Heitz, M.; Maroncelli, M. J. Phys. Chem. B 2004, 108 (18), 5771-5777.

(20) Arzhantsev, S.; Jin, H.; Baker, G. A.; Maroncelli, M. J. Phys. Chem. B 2007, 111 (18), 4978-4989.

(21) Chakrabarty, D.; Seth, D.; Chakraborty, A.; Sarkar, N. J. Phys. Chem. B 2005, 109 (12), 5753-5758.

(22) Seth, D.; Chakraborty, A.; Setua, P.; Sarkar, N. J. Phys. Chem. B 2007, 111 (18), 4781-4787.

(23) Seth, D.; Sarkar, S.; Sarkar, N. J. Phys. Chem. B 2008, 112 (9), 2629-2636.

(24) Xiao, D.; Rajian, J. R.; Li, S. F.; Bartsch, R. A.; Quitevis, E. L. J. Phys. Chem. B 2006, 110 (33), 16174-16178.

(25) Xiao, D.; Rajian, J. R.; Cady, A.; Li, S. F.; Bartsch, R. A.; Quitevis, E. L. J. Phys. Chem. B 2007, 111 (18), 4669-4677.

(26) Xiao, D.; Rajian, J. R.; Hines, L. G.; Li, S. F.; Bartsch, R. A.; Quitevis, E. L. J. Phys. Chem. B 2008, 112 (42), 13316-13325.

(27) Xiao, D.; Hines, L. G.; Bartsch, R. A.; Quitevis, E. L. J. Phys. Chem. B 2009, 113 (14), 4544-4548.

(28) Yang, P.; Voth, G. A.; Xiao, D.; Hines, L. G.; Bartsch, R. A.; Quitevis, E. L. J. Chem. Phys. 2011, 135 (3), 034502-1-034502-12.

(29) Adhikari, A.; Sahu, K.; Dey, S.; Ghosh, S.; Mandal, U.; Bhattacharyya, K. J. Phys. Chem. B 2007, 111 (44), 12809-12816.

(30) Dey, S.; Adhikari, A.; Das, D. K.; Sasmal, D. K.; Bhattacharyya, K. J. Phys. Chem. B 2009, 113 (4), 959-965.

(31) Bhattacharyya, K. J. Phys. Chem. Lett. 2010, 1 (21), 3254-3255.

(32) Sasmal, D. K.; Sen Mojumdar, S.; Adhikari, A.; Bhattacharyya, K.

J. Phys. Chem. B 2010, 114 (13), 4565-4571.
(33) Sasmal, D. K.; Mandal, A. K.; Mondal, T.; Bhattacharyya, K. J. Phys. Chem. B 2011, 115 (24), 7781-7787.

(34) Chowdhury, P. K.; Halder, M.; Sanders, L.; Calhoun, T.; Anderson, J. L.; Armstrong, D. W.; Song, X.; Petrich, J. W. J. Phys. Chem. B 2004, 108 (29), 10245-10255.

(35) Headley, L. S.; Mukherjee, P.; Anderson, J. L.; Ding, R. F.; Halder, M.; Armstrong, D. W.; Song, X. Y.; Petrich, J. W. J. Phys. Chem. A 2006, 110 (31), 9549-9554.

(36) Mukherjee, P.; Crank, J. A.; Halder, M.; Armstrong, D. W.; Petrich, J. W. J. Phys. Chem. A 2006, 110 (37), 10725-10730.

(37) Urahata, S. M.; Ribeiro, M. C. C. J. Chem. Phys. 2004, 120 (4), $1855-1863$.

(38) Wang, Y. T.; Voth, G. A. J. Am. Chem. Soc. 2005, 127 (35), 12192-12193.

(39) Lopes, J.; Padua, A. A. H. J. Phys. Chem. B 2006, 110 (7), 33303335.

(40) Lopes, J. N. C.; Gomes, M. F. C.; Padua, A. A. H. J. Phys. Chem. B 2006, 110 (34), 16816-16818.

(41) Wang, Y. T.; Voth, G. A. J. Phys. Chem. B 2006, 110 (37), 18601-18608.

(42) Ma, X. N.; Yan, L. Y.; Wang, X. F.; Guo, Q. J.; Xia, A. D. J. Phys. Chem. A 2011, 115 (27), 7937-7947.

(43) Paul, A.; Samanta, A. J. Phys. Chem. B 2008, 112 (51), $16626-$ 16632.

(44) Wang, J. J.; Tian, Y.; Zhao, Y.; Zhuo, K. Green Chem. 2003, 5 (5), 618-622.

(45) Widegren, J. A.; Laesecke, A.; Magee, J. W. Chem. Commun. 2005, 12, 1610-1612.

(46) Li, W. J.; Zhang, Z. F.; Han, B. X.; Hu, S. Q.; Xie, Y.; Yang, G. Y. J. Phys. Chem. B 2007, 111 (23), 6452-6456.

(47) Baker, S. N.; Baker, G. A.; Bright, F. V. Green Chem. 2002, 4 (2), 165-169.

(48) Harifi-Mood, A. R.; Habibi-Yangjeh, A.; Gholami, M. R. J. Phys. Chem. B 2006, 110 (13), 7073-7078.

(49) Mellein, B. R.; Aki, S.; Ladewski, R. L.; Brennecke, J. F. J. Phys. Chem. B 2007, 111 (1), 131-138.

(50) Paul, A.; Samanta, A. J. Phys. Chem. B 2008, 112 (3), 947-953.

(51) Sarkar, S.; Pramanik, R.; Ghatak, C.; Setua, P.; Sarkar, N. J. Phys. Chem. B 2010, 114 (8), 2779-2789.

(52) Chakrabarty, D.; Chakraborty, A.; Seth, D.; Hazra, P.; Sarkar, N. Chem. Phys. Lett. 2004, 397 (4-6), 469-474.

(53) Chakrabarty, D.; Chakraborty, A.; Seth, D.; Sarkar, N. J. Phys. Chem. A 2005, 109 (9), 1764-1769.

(54) Pramanik, R.; Rao, V. G.; Sarkar, S.; Ghatak, C.; Setua, P.; Sarkar, N. J. Phys. Chem. B 2009, 113 (25), 8626-8634.

(55) Trivedi, S.; Pandey, S. J. Phys. Chem. B 2011, 115 (22), 74057416.

(56) Sarkar, A.; Trivedi, S.; Pandey, S. J. Phys. Chem. B 2009, 113 (21), 7606-7614.

(57) Sarkar, A.; Trivedi, S.; Baker, G. A.; Pandey, S. J. Phys. Chem. B 2008, 112 (47), 14927-14936.

(58) Ito, N.; Arzhantsev, S.; Maroncelli, M. Chem. Phys. Lett. 2004, $396(1-3), 83-91$.

(59) Baker, G. A.; Baker, S. N.; McCleskey, T. M. Chem. Commun. 2003, 23, 2932-2933.

(60) Fletcher, K. A.; Pandey, S. J. Phys. Chem. B 2003, 107 (48), 13532-13539.

(61) Karmakar, R; Samanta, A. Chem. Phys. Lett. 2003, 376 (5-6), 638-645.

(62) Pandey, S.; Fletcher, K. A.; Baker, S. N.; Baker, G. A. Analyst 2004, 129 (7), 569-573.

(63) Lakowicz, J. R. Principles of Fluorescence Spectroscopy, 3rd ed.; Springer: New York, 2006; pp 361-363.

(64) Jordanides, X. J.; Lang, M. J.; Song, X. Y.; Fleming, G. R. J. Phys. Chem. B 1999, 103 (37), 7995-8005.

(65) Smith, T. A.; Bajada, L. M.; Dunstan, D. E. Macromolecules 2002, 35 (7), 2736-2742. 
(66) Lee, K. C. B.; Siegel, J.; Webb, S. E. D.; Leveque-Fort, S.; Cole, M. J.; Jones, R.; Dowling, K.; Lever, M. J.; French, P. M. W. Biophys. J. 2001, 81 (3), 1265-1274.

(67) Holgado, M.; de Schaefer, C. R.; Arancibia, E. L. J. Chem. Eng. Data 2002, 47 (2), 144-148.

(68) Guo, X. M.; Wang, S. F.; Xia, A. D.; Su, H. M. J. Phys. Chem. A 2007, 111 (26), 5800-5805.

(69) Szajdzinska-Pietek, E.; Wolszczak, M.; Plonka, A.; Schlick, S. J. Am. Chem. Soc. 1998, 120 (17), 4215-4221.

(70) Pandey, S.; Redden, R. A.; Fletcher, K. A.; Palmer, C. P. Macromol. Chem. Phys. 2003, 204 (3), 425-435.

(71) Szajdzinska-Pietek, E.; Pinteala, M.; Schlick, S. Polymer 2004, 45 (12), 4113-4120.

(72) Acree, W. E.; Wilkins, D. C.; Tucker, S. A.; Griffin, J. M.; Powell, J. R. J. Phys. Chem. 1994, 98 (10), 2537-2544. 